\title{
Solid Oxide Fuel Cells: Recent Scientific and Technological Advancements
}

\author{
SOUMENDRA N. BASU (i) ${ }^{1,2,4}$ and AMIT PANDEY ${ }^{3,5}$ \\ 1.-Division of Materials Science and Engineering, Boston University, Brookline, MA 02446 \\ USA. 2.-Department of Mechanical Engineering, Boston University, Boston, MA 02215, USA. \\ 3.-ANSYS Inc, Canonsburg, PA 15317, USA. 4.-e-mail: basu@bu.edu. 5.-e-mail: \\ dramitpandey@gmail.com
}

Solid oxide fuel cells (SOFCs) are high-temperature electrochemical devices that directly convert the chemical energy of the fuel to electrical energy at high efficiency, thereby mitigating the Carnot cycle limitations of gas turbines. Also, unlike proton-exchange membrane (PEM) fuel cells, SOFCs are fuel flexible, and can directly use abundantly available fuels like methane. Finally, SOFCs produce carbon dioxide that can be easily sequestered, and do not produce $\mathrm{NO}_{\mathrm{X}}$. SOFCs can also be easily deployed for distributed power generation.

At the cell level, the electrodes (anode and cathode) and electrolyte have materials and processing challenges, while at the stack level, the same goes for interconnections. The first paper, "TiN-Ni Cermets with High Oxidation Resistance and Electrical Conductivity as Candidates for the Intermediate Temperature Solid Oxide Fuel Cell Interconnects" led by Hang Duan et al., argues that TiN-Ni cermets that have high electrical conductivity due to the Ni phase also have acceptable longterm oxidation resistance to be considered as an interconnection material. The next paper, "Thermal and Electrical Properties of Highly Dense Ceramic Materials Based on Co-Doped $\mathrm{LaYO}_{3}$ " led by Dmitry Medvedev, makes a case for doped $\mathrm{LaYO}_{3}$ being a suitable electrolyte material for proton-conducting SOFCs. The next paper entitled, "Effect of Titania Doping on Structural and Mechanical Properties of NiO/YSZ Anode Materials Sintered by Using Microwave Energy" led by Kanchan Singh, argues that microwave sintered NiO-YZT [titania-doped yttriastabilized zirconia (YSZ)] composites are suitable for producing Ni-YSZ cermets for SOFC anodes. The next paper, "Comparative Study of Yttria-Stabilized Zirconia Synthesis by Co-Precipitation and

Soumendra N. Basu and Amit Pandey are the guest editors for the invited topic Solid Oxide Fuel Cells: Recent Scientific and Technological Advancements in this issue.
Solvothermal Methods" led by Jie Xiao, demonstrates that both co-precipitation and solvothermal methods produce nanocrystalline YSZ powders for use as electrolyte materials.

The paper "Thermodynamic and Experimental Evaluation of $\mathrm{La}_{1-x} \mathrm{Sr}_{x} \mathrm{MnO}_{3 \pm \delta}$ Cathode in Presence of Cr-Containing Humidified Air" led by Shadi Darvish studies the chromium poisoning of strontium-doped lanthanum manganite cathodes, and addresses the thermodynamics of the poisoning phenomenon. The next paper, "Interpretation of Impedance Spectra of Solid Oxide Fuel Cells: $L$ Curve Criterion for Determination of Regularization Parameter in Distribution Function of Relaxation Times Technique" led by Kyung Joong Yoon, introduces a new $L$-curve criterion as a reliable graphical tool for proper interpretation of electrochemical impedance spectroscopy data to obtain the distribution function of relaxation times. The next paper, "Co-infiltration of Nickel and Mixed Conducting $\mathrm{Gd}_{0.1} \mathrm{Ce}_{0.9} \mathrm{O}_{2-\delta}$ and $\mathrm{La}_{0.6} \mathrm{Sr}_{0.3} \mathrm{Ni}_{0.15}$ $\mathrm{Cr}_{0.85} \mathrm{O}_{3-\delta}$ Phases in Ni-YSZ Anodes for Improved Stability and Performance" led by Soumendra Basu, looks at co-infiltration of $\mathrm{Ni}$ with two different mixed ionic electronic conducting oxides for longterm improvement of anodic catalytic activity in SOFCs. The last paper, "Improved Tolerance of Lanthanum Nickelate $\left(\mathrm{La}_{2} \mathrm{NiO}_{4+\delta}\right)$ Cathodes to Chromium Poisoning Under Current Load in Solid Oxide Fuel Cells" led by Srikanth Gopalan, looks at the tolerance of lanthanum nickelate cathodes to chromium poisoning.

The following list summarizes the papers being published under the topic of Solid Oxide Fuel Cells: Recent Scientific and Technological Advancements. To download any of the papers, follow the URL: $h$ ttps://link.springer.com/journal/11837/71/11/page/1 to the table of contents page of the November 2019 issue (vol. 71, no. 11). 
- "TiN-Ni Cermets with High Oxidation Resistance and Electrical Conductivity as Candidates for the Intermediate Temperature Solid Oxide Fuel Cell Interconnects" by Hang Duan, Yan Liu, Qian Qi, Hui Zhang, and Zhengren Huang

- "Thermal and Electrical Properties of Highly Dense Ceramic Materials Based on Co-Doped $\mathrm{LaYO}_{3}$ " by A. Kasyanova" Liana Tarutina, Julia Lyagaeva, Gennady Vdovin, Dmitry Medvedev, and Anatoly Demin

- "Effect of Titania Doping on Structural and Mechanical Properties of NiO/YSZ Anode Materials Sintered by Using Microwave Energy" by Sonia Mago, Kanchan L. Singh, Anirudh P. Singh, Chetan Sharma, and Payal Sharma

- "Comparative Study of Yttria-Stabilized Zirconia Synthesis by Co-Precipitation and Solvothermal Methods" by Yang Li, Qiaolin Han, Yao Yao, Mian Li, Peng Dong, Lina Han, Xiaoyuan Zeng, Jiang Liu, Jiaming Liu, Yingjie Zhan, and Jie Xiao

- "Thermodynamic and Experimental Evaluation of $\mathrm{La}_{1-x} \mathrm{Sr}_{x} \mathrm{MnO}_{3 \pm \delta}$ Cathode in the Presence of Cr-Containing Humidified Air" by Shadi Darvish, Boxun $\mathrm{Hu}$, Prabhakar Singh, and $\mathrm{Yu}$ Zhong
- "Interpretation of Impedance Spectra of Solid Oxide Fuel Cells: $L$-Curve Criterion for Determination of Regularization Parameter in Distribution Function of Relaxation Times Technique" by Moon-Bong Choi, Jisu Shin, Ho-Il Ji, Hyoungchul Kim, Ji-Won Son, Jong-Ho Lee, ByungKook Kim, Hae-Weon Lee, and Kyung Joong Yoon

- "Co-infiltration of Nickel and Mixed Conducting $\mathrm{Gd}_{0.1} \mathrm{Ce}_{0.9} \mathrm{O}_{2-\delta}$ and $\mathrm{La}_{0.6} \mathrm{Sr}_{0.3} \mathrm{Ni}_{0.15} \mathrm{Cr}_{0.85} \mathrm{O}_{3-\delta}$ Phases in Ni-YSZ Anodes for Improved Stability and Performance" by Yanchen Lu, Paul Gasper, Alexey Y. Nikiforov, Uday B. Pal, Srikanth Gopalan, and Soumendra N. Basu

- "Improved Tolerance of Lanthanum Nickelate $\left(\mathrm{La}_{2} \mathrm{NiO}_{4+\delta}\right)$ Cathodes to Chromium Poisoning Under Current Load in Solid Oxide Fuel Cells" by Yiwen Gong, Ruofan Wang, Jane Banner, Soumendra N. Basu, Uday B. Pal, and Srikanth Gopalan.

Publisher's Note Springer Nature remains neutral with regard to jurisdictional claims in published maps and institutional affiliations. 